\title{
Karyotype differentiation and reproductive isolation among natural popula- tions of Drosophila lacertosa
}

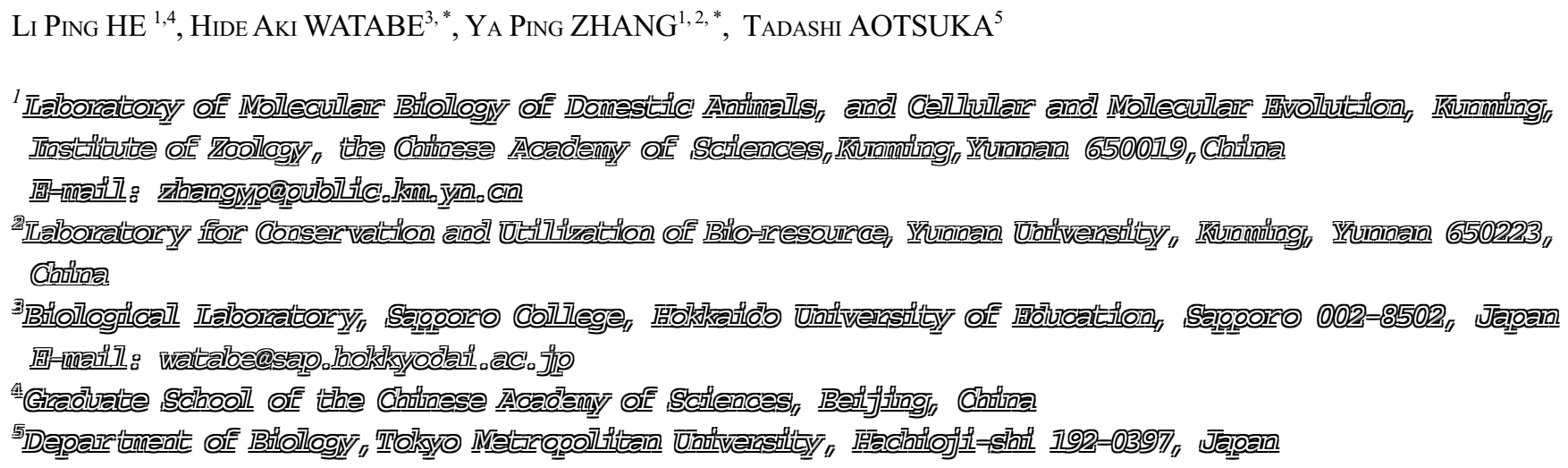

\begin{abstract}
Drosophila lacertosa is widely distributed from northern India to Far East of Russia throughout China. We have studied geographical distributions of three kinds of chromosomal karyotypes, type $D(2 n=10,4$ pairs of V-shaped metacentric chromosomes and a pair of micro-chromosomes), type $\mathrm{L}(2 \mathrm{n}=10,5 \mathrm{~V}$ with a pair of large-sized heterochromatic autosomes) and type $\mathrm{M}(2 \mathrm{n}=10,5 \mathrm{~V}$ with middle-sized ones). Type $\mathrm{D}$ was found exclusively in local populations of $D$. lacertosa distributed in Yun-Gui Plateau, southwestern China. Both type L and M have a wide range of distribution, and the former occurred in subtropical regions of China including Taiwan Island, whereas the latter in cool temperate regions of East Asia covering Far East of Russia, Korea and the Japan Islands. A strong premating isolation was detected between flies with type $\mathrm{D}$ and those with type $\mathrm{L}$ or M. These data demonstrate that genetic differentiation leading to cryptic speciation might have occurred in natural populations of Drosophila lacertosa.
\end{abstract}

Key words: Drosophila lacertosa, karyotype differentiation, geographic distribution, reproductive isolation, cryptic speciation.

\section{INTRODUCTION}

Genetic differentiation may occur at different levels of the genome during the course of evolution. Characterization of mitotic metaphase chromosomes to determine chromosome number and morphology is a very important step in cytotaxonomic studies. Analyses of chromosomal karyotypes have provided us with valuable information on organic evolution[1]. Karyotype variation has been found not only among closely related species but also within one species[2-8]. Thus, cryptic and sibling species, or incipient speciation, has been frequently detected first at the cytological level for some insect species[9-13].

*Corresponding author: Dr. Ya Ping Zhang, Fax: 0871-5195430; Tel: 0871-5190761,E-mail: zhangyp@public.km.yn.cn,

and Dr. Hide-aki WATABE, E-mail: watabe@sap.hokkyodai.ac.jp, Tel: 0081-11-778-0342, Fax: 0081-11-778-8822

Received May-14-2003 Revised July-9-2003 Accepted July-25-2003
The Drosophila robusta species group distributed in the Holarctic Region has been well studied from an evolutionary point of view by North American researchers [14], and D. lacertosa is the most widely distributed species within the robusta group, ranging from northern India to Far East of Russia throughout China. Two kinds of metaphase karyotypes were previously recorded in natural populations of $D$. lacertosa, i.e., $2 \mathrm{n}=10$ with 5 pairs of metacentrics from a Japan strain and $2 n=10$ with 4 pairs of metacentrics and 1 pair of microcromosomes from a Kunming strain[15-17].

In this study, we karyologically examined a number of local populations of $D$. lacertosa, almost covering the known geographic range of this species. We identified a new karyotype with a pair of large heterochromatic autosomes in subtropical regions of China. Furthermore, reproductive isolation experiments were carried out for 
local strains with different karyotypes. Based on the results of chromosomal configuration, reproductive isolation and geographic distribution, we discussed genetic differentiation in natural populations of $D$. lacertosa.

\section{MATERIALS AND METHODS}

\section{Karyotype analyses}

All strains used in this study were established from a single wildcaught female from various localities listed in Table 1 . The flies were maintained in a glass vial containing cornmeal Drosophila medium, in incubators at $18 \pm 2^{\circ} \mathrm{C}$ under continuous light condition. Neuroblasts were dissected from $3^{\text {rd }}$ instar larvae in Ringer solution, treated with $0.1 \mathrm{mg} / \mathrm{ml}$ of colchicines solution, followed by $4 \%$ Giemsa staining, and then air-dried. Metaphase images were taken by Zeiss microscope, and Genus program was used to analyze the morphology of chromosomes. About 30 metaphase cells were analyzed for each strain.

\section{Reproductive isolation}

Five geographic strains with three different kinds of karyotypes were studied: 3 strains with type D from Kunming (KM), Lijiang (LJ) and Lugu Lake (LG) in Yunnan Province, 1 strain with type L from Shennongiia (SNJ) in Hubei Province, and 1 strain with type M from Ishikari (IS) in northern Japan. All strains had been determined cytogenetically before cross-experiments. Newly emerged flies were slightly etherized for sex identification within $24 \mathrm{~h}$ after adult eclosion, and females and males were transferred into glass vials separately. The 12 to 14 day-old flies were used for all crosses. Pre-mating isolation was studied by no choice method. Five males and the same number of females with different karyotypes were placed together in a vial and maintained for 4 days. Then, the females were dissected in Ringer solution and examined for sperm in seminal receptacles and spermathecae. The 14 to 16 replications were made for each cross. Pre-mating isolation was evaluated by Isolation Index (I.I.), calcu-

frequency of inseminated females in inter-karyot crosses $(=\mathrm{A}$ 旅 $\times \mathrm{B}$ 旗

I.I. $=1-$

frequency of inseminated females in intra-karyotypic crosses

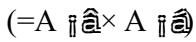

lated by the following formula:

where A and B each represents a strain of D. lacertosa with the different karyotype. As for the presence of post-mating isolation, fertility and viability of $F_{1}$ hybrid obtained from inter-karyotypic crosses were examined. Since it is very difficult to rear one pair of wild drosophilid flies and it is nearly impossible to check the viability of a single larva for the development from egg to adult eclosion, we adopted "mass-culture experiment" described below for examining the viability of $F_{1}$ hybrid. Five females and 5 males were kept in a vial together a few days. When eggs were deposited on the surface of the vials, the following development was observed until adult eclosion. If the number of $F_{1}$ hybrid in a vial is not significantly less than that in the control one, it is considered to be fully viable. The degree of viability of $F_{1}$ hybrid was tentatively given by the ratio of the number of vials in which $F_{1}$ hybrid fully developed to the adult stage over the total number of vials observed. The development time (days) of $F_{1}$ hybrid was calculated as number of days for $F_{1}$ hybrid to develop from embryogenesis to emergence of adult fly. To check fertility of $F_{1}$ males and females, reciprocal crosses were made between $F_{1}$ hybrid flies and the respective parental lines. Fertility tests were repeated 10-17 times for each cross. The software of statistic Win was used for significant test.

\section{RESULTS}

\section{Karyotypic variation and geographic distribution}

Figure 1 shows male metaphase configurations of six geographic strains of $D$. lacertosa. In all strains, the
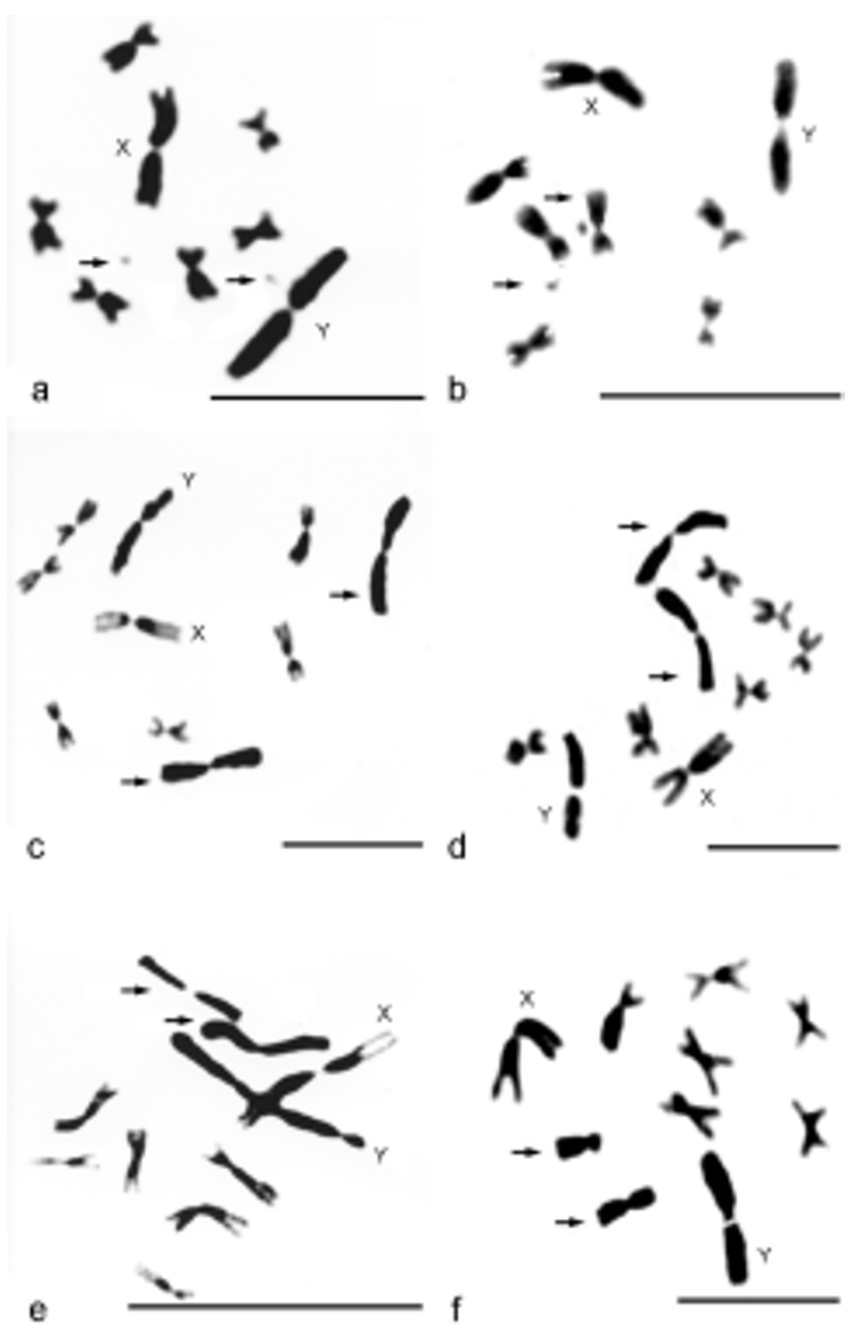

Fig 1. Male metaphase chromosomes from larval neuroblast cells of Drosophila lacertosa. Figs. 1a-b: type D from Mt. Ailao, Yunnan (a) and Kunming, Yunnan (b); c-d: type L from Mt. Wuyi, Fujian (c) and Mt. Shiwan, Guangxi (d); type M from Jusso, Kagoshima, Kyushu, Japan (e) and Kikonai, Hokkaido, Japan (f). Microchromosomes (ab) and heterochromatic chromosomes (c-f) are indicated by arrows. Scale unit $=10 \mu \mathrm{m}$. 
number of chromosomes was $2 n=10$ comprising 3 pairs of metacentric ( $\mathrm{V}$-shaped) autosomes, a pair of sex chromosomes $(\mathrm{X}=\mathrm{V}, \mathrm{Y}=\mathrm{V})$, and a pair of 5th autosomes with variable sizes. Three kinds of chromosomal karyotypes were observed and tentatively named according to the characteristics of variable 5 th chromosomes: type D (dotshaped), L (long-sized) and M (medium-sized) as illustrated in Fig 1a-b, c-d and e-f, respectively. Type D was previously reported from a Kunming strain by Ling and Zhang[16]. The other two types can be easily identified from each other by the length ratio of 5th heterochromatic autosome/X chromosome (Tab 1). Type M was originally described in a Japanese strain by Watabe et al[17], with the ratio of heterochromosome/X chromosome being less than 1.0. In type L, however, the length ratio is clearly larger than 1.0, and this karyotype is a newly found one during in our study.

The length ratios of $5 \mathrm{th} / \mathrm{X}$ chromosome for 19 geographic strains of $D$. lacertosa were summarized in Table 1. Among type L strains, the length ratio varied from 1.26 in a Simao strain to 1.36 in a Chitou strain, whereas within type $\mathrm{M}$ strains, it ranges from 0.48 in a Kikonai strain from northern Japan to 0.83 in an Ussuri strain. No significant difference ( $p>0.05$ ) was detected between geographical strains with the same karyotype of $L$ or $M$. The length ratios of eight Japanese strains were all less than 0.62 , and two Korean strains were closer to an Ussuri strain than to any Japanese strains in the length ratio. This suggests that gene flow may be limited between the continental populations and the

Tab 1. Metaphase configuration and the length ratio of 5th heterochromatic autosome / X chromosome in 23 local populations of Drosophila lacertosa.

\begin{tabular}{|c|c|c|c|c|}
\hline \multirow[t]{2}{*}{ Local strains } & \multirow{2}{*}{$\begin{array}{l}\text { Metaphase } \\
\text { composition }\end{array}$} & \multicolumn{2}{|c|}{ Length ratio } & \multirow[t]{2}{*}{ Type $^{3}$} \\
\hline & & mean \pm SD $(n)^{1}$ & Range $^{2}$ & \\
\hline \multicolumn{5}{|l|}{ China } \\
\hline Mt. Emei, Sichuan Province & $2 \mathrm{n}=10(5 \mathrm{~V})$ & $1.27 \pm 0.13(30)$ & $1.08-1.50$ & $\mathrm{~L}$ \\
\hline Shennongjia, Hubei Province & $2 \mathrm{n}=10(5 \mathrm{~V})$ & $1.34 \pm 0.13(30)$ & $1.17-1.64$ & $\mathrm{~L}$ \\
\hline Chitou, Taiwan & $2 n=10(5 V)$ & $1.36 \pm 0.18(32)$ & $1.10-1.75$ & $\mathrm{~L}$ \\
\hline Fushan, Taiwan & $2 n=10(5 V)$ & $1.29 \pm 0.15(30)$ & $1.11-1.60$ & $\mathrm{~L}$ \\
\hline Mt. Wuyi, Fujian Province & $2 \mathrm{n}=10(5 \mathrm{~V})$ & $1.33 \pm 0.13(40)$ & $1.14-1.62$ & $\mathrm{~L}$ \\
\hline Mt. Shiwan, Guangxi Province & $2 n=10(5 V)$ & $1.34 \pm 0.05(29)$ & $1.31-1.42$ & $\mathrm{~L}$ \\
\hline Mt. Leigong, Guizhou Province & $2 \mathrm{n}=10(4 \mathrm{~V}+1 \mathrm{D})$ & - & - & $\mathrm{D}$ \\
\hline Simao, Yunnan Province & $2 \mathrm{n}=10(5 \mathrm{~V})$ & $1.26 \pm 0.13(25)$ & $1.15-1.47$ & $\mathrm{~L}$ \\
\hline Lijiang, Yunnan Province & $2 \mathrm{n}=10(5 \mathrm{~V})$ & $1.29 \pm 0.12(22)$ & $1.15-1.44$ & $\mathrm{~L}$ \\
\hline Lijiang, Yunnan Province & $2 \mathrm{n}=10(4 \mathrm{~V}+1 \mathrm{D})$ & - & - & $\mathrm{D}$ \\
\hline Mt. Ailao, Yunnan Province & $2 \mathrm{n}=10(4 \mathrm{~V}+1 \mathrm{D})$ & - & - & $\mathrm{D}$ \\
\hline Lugu Lake, Yunnan Province & $2 n=10(4 V+1 D)$ & - & - & $\mathrm{D}$ \\
\hline Kunming, Yunnan Province & $2 n=10(4 V+1 D)$ & - & - & $\mathrm{D}$ \\
\hline \multicolumn{5}{|l|}{ Korea } \\
\hline Chulchon, Kanwon & $2 \mathrm{n}=10(5 \mathrm{~V})$ & $0.73 \pm 0.10(30)$ & $0.55-0.90$ & M \\
\hline Genshu, Kanwon & $2 \mathrm{n}=10(5 \mathrm{~V})$ & $0.72 \pm 0.07(30)$ & $0.57-0.83$ & M \\
\hline \multicolumn{5}{|l|}{ Russia } \\
\hline Ussuri, Far East & $2 \mathrm{n}=10(5 \mathrm{~V})$ & $0.83 \pm 0.13(38)$ & $0.50-1.00$ & M \\
\hline \multicolumn{5}{|l|}{ Japan } \\
\hline Tonebetsu, Hokkaido & $2 \mathrm{n}=10(5 \mathrm{~V})$ & $0.58 \pm 0.09(30)$ & $0.38-0.70$ & M \\
\hline Kikonai, Hokkaido & $2 \mathrm{n}=10(5 \mathrm{~V})$ & $0.48 \pm 0.08(30)$ & $0.25-0.67$ & M \\
\hline Hachiohji, Tokyo & $2 \mathrm{n}=10(5 \mathrm{~V})$ & $0.57 \pm 0.10(38)$ & $0.36-0.75$ & M \\
\hline Mt. Takao, Tokyo & $2 \mathrm{n}=10(5 \mathrm{~V})$ & $0.54 \pm 0.10(30)$ & $0.30-0.70$ & M \\
\hline Nogouchi, Fukuoka & $2 \mathrm{n}=10(5 \mathrm{~V})$ & $0.62 \pm 0.10(30)$ & $0.44-0.86$ & M \\
\hline Tsushima Is., Nagasaki & $2 \mathrm{n}=10(5 \mathrm{~V})$ & $0.52 \pm 0.09(30)$ & $0.38-0.71$ & M \\
\hline Jusso, Kagoshima & $2 \mathrm{n}=10(5 \mathrm{~V})$ & $0.56 \pm 0.09(38)$ & $0.38-0.75$ & M \\
\hline Yakushima Is., Kagoshima & $2 \mathrm{n}=10(5 \mathrm{~V})$ & $0.59 \pm 0.08(30)$ & $0.43-0.71$ & M \\
\hline
\end{tabular}

${ }^{1}$ The number of chromosomes examined; ${ }^{2}$ minimum-maximum; ${ }^{3} \mathrm{~L}$, with large-sized heterochromatic chromosomes; M, with middle-sized chromosomes; D, with microchromosomes. 
island population of $D$. lacertosa.

The geographic range of distribution of different karyotypes in local populations of $D$. lacertosa was shown in Fig 2. Type D is exclusively restricted to Yunnan Province and a part of Guizhou, while Type L is common in southern China including Taiwan Island, and type $M$ is distributed in northeastern regions of East Asia including Japan, Korea and Far East of Russia.

\section{Reproductive isolation}

Table 2 shows the percentage of inseminated females in the crosses between five pairs of geographic strains with different karyotypes. These data represent percen-tage of females with sperm, which is inversely correlated with pre-mating isolation index (see "Materials and Methods"). Thus, no pre-mating isolation was observed for geographic strains within the same karyotype. Although the isolation index between

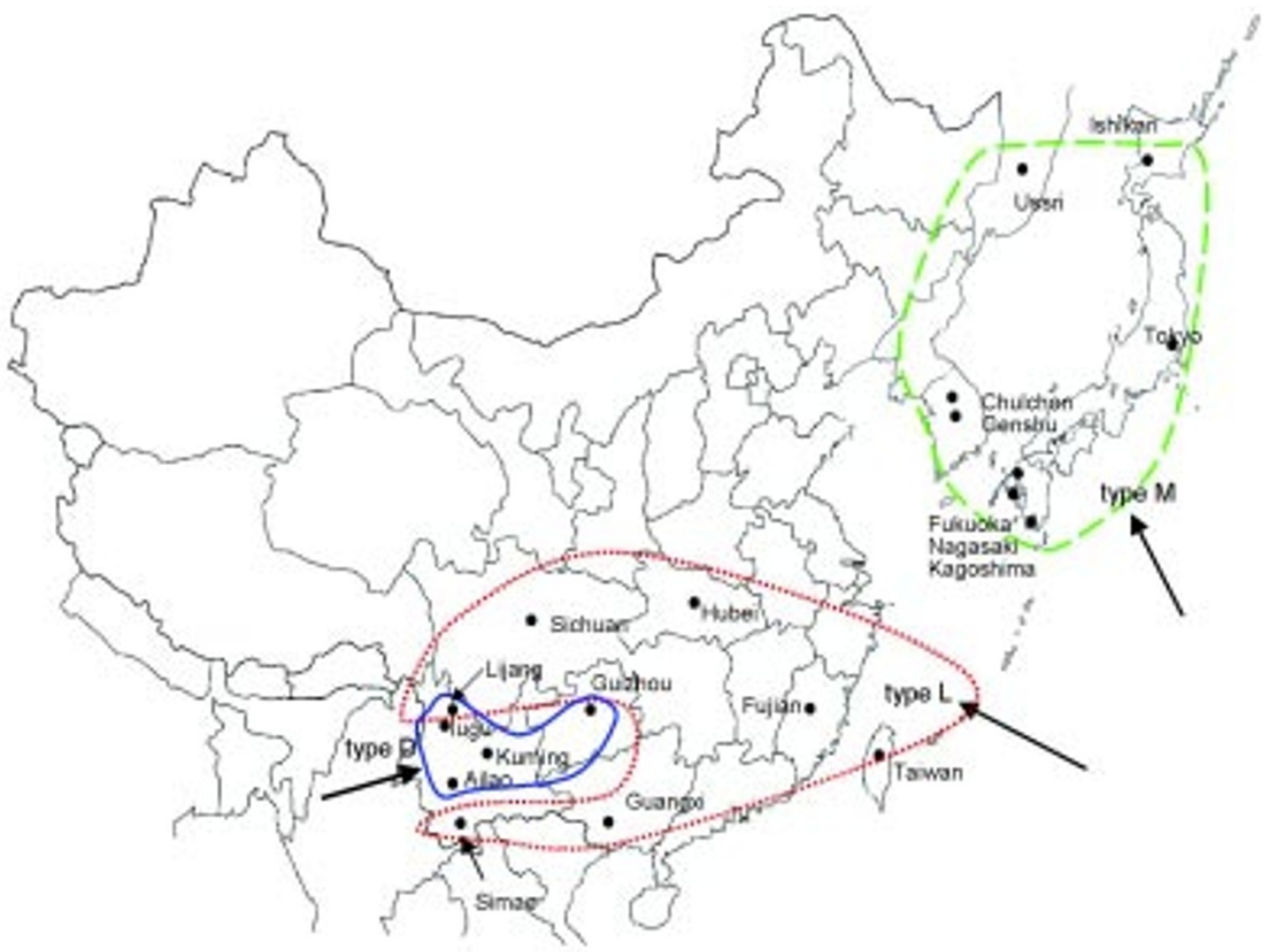

Fig 2. Map of East Asia showing the geographic distribution ranges of three kinds of karyotypes in natural populations of Drosophila lacertosa. Closed circles cover collection localities where flies were studied karyologically.

Tab 2. The percentages of inseminated females in the crosses between different karyotypic strains of Drosophila lacertosa from Mt. Ailao (AL), Lugu Lake (LG), Kunming (KM), Shennongjia (SNJ) and Ishikari (IS), by no choice method.

\begin{tabular}{|c|c|c|c|c|c|}
\hline 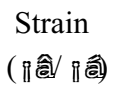 & $\begin{array}{c}\mathrm{AL} \\
\text { (type D) }\end{array}$ & $\begin{array}{l}\text { LG } \\
\text { (type D) }\end{array}$ & $\begin{array}{c}\text { KM } \\
\text { (type D) }\end{array}$ & $\begin{array}{c}\text { SNJ } \\
\text { (type L) }\end{array}$ & $\begin{array}{c}\text { IS } \\
\text { (type M) }\end{array}$ \\
\hline $\mathrm{AL}$ & $98.5(68)$ & $100.0(60)$ & $100.0(40)$ & $3.8(77)$ & $0(82)$ \\
\hline LG & $100.0(83)$ & $100.0(68)$ & I & $7.5(67)$ & $3.5(84)$ \\
\hline KM & $100.0(56)$ & I & $100.0(65)$ & 0 (29) & I \\
\hline SNJ & $7.6(78)$ & $2.0(100)$ & $0(30)$ & 93.4 (79) & $78.7(80)$ \\
\hline IS & $17.4(86)$ & $7.8(90)$ & / & 93.7 (79) & $96.6(59)$ \\
\hline
\end{tabular}


Tab 3. Viability of $F_{1}$ offspring as shown by percentages of the vials with adult flies emerged/the total vials observed, and the rate of development from egg to adult eclosion in $\mathrm{F}_{1}$ offspring derived from crosses between type M (IS: Ishikari, Japan) and type L (Shennongjia, Hubei) strains, and between three strains of type D (LG: Lugu Lake; AL: Mt. Ailao; KM, Kunming).

\begin{tabular}{|c|c|c|}
\hline 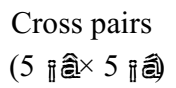 & $\begin{array}{l}\text { Viability }(\%) \text { of } \\
\mathrm{F}_{1} \text { offspring }\end{array}$ & $\begin{array}{l}\mathrm{F}_{1} \text { development } \\
\text { time mean } \pm \mathrm{SE}\end{array}$ \\
\hline
\end{tabular}

Cross between $\mathrm{L}$ and $\mathrm{M}$ type strain

\begin{tabular}{|c|c|c|}
\hline 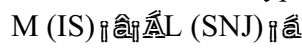 & 94.1 (17) & $24.8 \pm 0.6$ \\
\hline 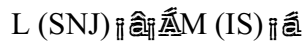 & $94.1(17)$ & $24.4 \pm 0.8$ \\
\hline Control cross & $90.9(22)$ & $25.7 \pm 0.9$ \\
\hline
\end{tabular}

Cross between different geographical strain within Type Ds

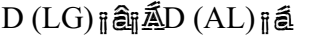
$100.0(15)$
$26.8 \pm 2.1$

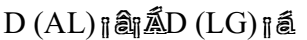
$83.3(12)$
$26.5 \pm 1.9$

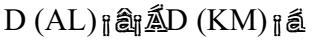
$100.0(9)$
$27.0 \pm 1.2$

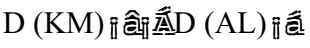
$81.8(11)$
$27.1 \pm 1.1$
Control cross
$100.0(14)$
$26.9 \pm 1.2$

The number in parentheses gives the number of vials observed.

Tab 4. Fertility as indicated by percentages of the vials with adults emerged/the total vials examined inthe crosses between Shennongjia (SNJ) and Ishikari (IS) strain of Drosophila lacertosa.

\begin{tabular}{|c|c|c|}
\hline Parental flies $((\mathrm{P}))$ & 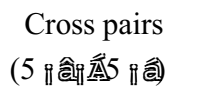 & $\begin{array}{l}\text { Percentage of } \mathrm{F}_{2} \\
\text { adults emerged }\end{array}$ \\
\hline \multirow[t]{3}{*}{ 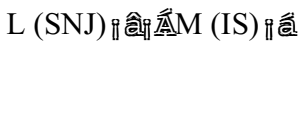 } & 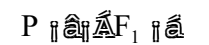 & $90.0(10)$ \\
\hline & 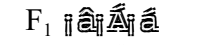 & $81.8(11)$ \\
\hline & 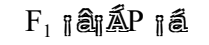 & $91.6(12)$ \\
\hline \multirow[t]{3}{*}{ 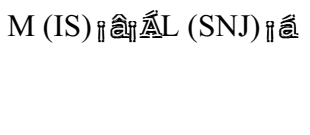 } & 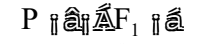 & $80.0(10)$ \\
\hline & 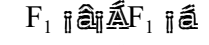 & $90.0(10)$ \\
\hline & 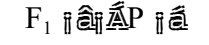 & $83.8(12)$ \\
\hline
\end{tabular}

The number in parentheses is the number of rearing vials observed.

type $\mathrm{M}$ females and type $\mathrm{L}$ males was slightly higher than that in its reciprocal cross, both values were not significantly different from zero. Furthermore, the sperms were active in all inseminated females. This data strongly suggest that there is no reproductive barrier between flies with type L and type M.
We further tested the viability of $F_{1}$ hybrids, as calculated by percentages of the vials with adult flies emerged/ the total vials observed. More than $90 \%$ of the vials had adult progeny in reciprocal crosses between type $M$ and $\mathrm{L}$ (Table 3), and the number of progeny is comparable to control crosses $(p>0.05)$. The development time required from egg to adult eclosion was around 25 days in all crosses. Development time in any crosses between L and $\mathrm{M}$ type were not significantly different from those of the control group ( $p>0.05)$. These results clearly indicate that $F_{1}$ hybrids derived from crosses between type $L$ and $M$ are fully viable at all developmental stages. Similar results on viability and development time were obtained among three geographic strains with type D. All crosses between different geographical strains produced $\mathrm{F}_{1}$ hybrid, and both viability and development time did not significantly deviate from those of the control crosses $(\mathrm{p}>0.05)$.

We next studied the fertility of $F_{1}$ hybrids from various crosses. As shown in Table 4, more than $80 \%$ of the crossed-vials produced progeny in all cross pairs. In the remaining vials, eggs hatched out in all vials, but larva died, probably due to mold contamination. These results indicate a nearly complete fertility of $F_{1}$ male from the crosses between type $\mathrm{L}$ and $\mathrm{M}$. In addition, the $\mathrm{F}_{1}$ hybrids from crosses between different geographic strains with type D were fully fertile for both sexes.

In contrast, the isolation indices between type $\mathrm{D}$ and $\mathrm{L}$ or $\mathrm{M}$ were higher than 0.8 , in both reciprocal crosses. Chi-square analyses show that there is no difference from the expected value of 1.0, an index of complete isolation, indicating a nearly complete pre-mating isolation between type $\mathrm{D}$ and $\mathrm{L}$ or $\mathrm{M}$. It was frequently observed that the sperms were quite inactive in seminal receptacles and spermathecae of inseminated females in these crosses. This also implies the presence of postmating isolation, gametic mortality, between type $\mathrm{D}$ and L or M[18].

\section{DISCUSSION}

Three kinds of chromosomal karyotypes, type D, L and $\mathrm{M}$, were found in natural populations of $D$. lacertosa. The common chromosome composition is $2 \mathrm{n}=10$, comprising 3 pairs of $\mathrm{V}$-shaped autosomes, sex chromosomes (V-shaped $\mathrm{X}$ and $\mathrm{Y}$ ) and a pair of dot-shaped autosomes or of variable 5th metacentric ones. The most remarkable difference is observed between type $\mathrm{D}$ and the other two types. Type D contains a pair of dot chromosomes 
and lacks a pair of heterochromatic autosomes, whereas type $\mathrm{L}$ and $\mathrm{M}$ have a pair of heterochromatic autosomes and lacks of the dot chromosomes.

The typical karyotype of the robusta species group is $2 n=12$ including 1 pair of micro-chromosomes[15, 17]. It is therefore reasonable to assume that a hypothetical ancestor of $D$. lacertosa might possess $2 \mathrm{n}=12$ with 1 pair of dots and 5 pairs of metacentric chromosomes. In Drosophila, the loss of dot chromosomes has often been reported, and dots are considered to be incorporated into a given chromosome in two different manners, e.g., an autosome-dot fusion in Drosophila willistoni, a neotropical member of the subgenus Sophophora, and an X-dot one in Asiatic Scaptodrosophila lebanonensis [19-20]. We propose that the dot chromosomes might have fused to other chromosomes, and this may have resulted in type L or M. Variation in the length of 5th chromosomes between type L and M may be explained by the gain or loss of heterochromatin, as such chromosomal changes have been frequently observed in many animals[21, 10]. Type D might have derived from an ancient karyotype, probably by the elimination of 5 th chromosomes into cytoplasm, although the role of heterochromatic chromosomes in the genome system of $D$. lacertosa is quite obscure. The results of reproductive isolation and geographic distribution strongly suggest that a chromosomal divergence of type $\mathrm{D}$ from a hypothetical ancestral form might have occurred earlier than those of type L and M (Fig 3). A further study on the banding patterns of polytene chromosomes is needed to ascertain our hypothesis.

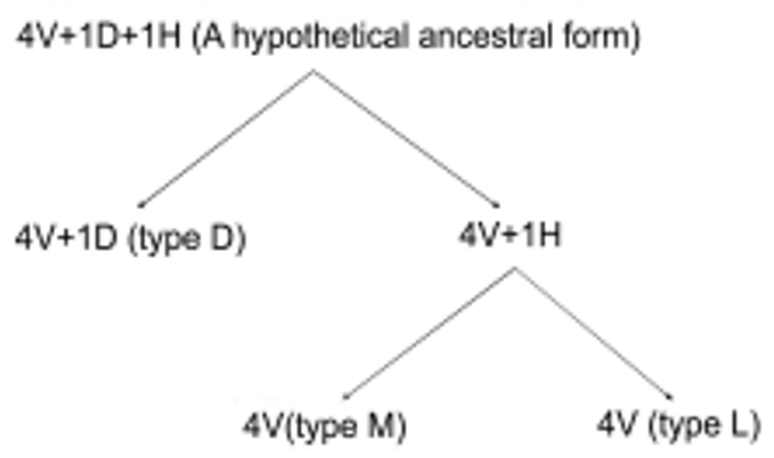

Fig 3. A hypothetical relationship of three kinds of karyotypes in Drosophila lacertosa. V: V-shape chromosomes; D: dot-shaped chromosome; H: heterchromatic chromosome.
In many regions of East Asia, Drosophila lacertosa inhabits streamsides in natural forests. In Yunnan, however, this species is rather common in secondary forests and near human habitations, and it was sometimes found in restaurants or kitchens as a domestic species [22-23]. This implies a possible adaptive mechanism of type D genotype to artificial environments. Although sample size for northern parts of China is relatively small, our data clearly show that type $\mathrm{L}$ and $\mathrm{M}$ are distributed allopatrically, the former in southern China with warm climates and the latter in northern regions of East Asia with cool climates. This suggests a possible climatic adaptation to latitudinal temperature cline.

It is well known that there are cryptic species in many taxonomic groups, which is indistinguishable to each other at the morphological level, but can be identified at the genetic level[9-13, 24]. Drosophila lacertosa populations have various degrees of karyotypic differentiation. Although no significant discriminative differences have been detected in the external morphology and genitalia [22], pre-mating isolation is nearly complete between type D and type L or M. Interestingly, our unpublished sequence data on mitochondrial ND2 gene showed a clear-cut correlation between karyotypic variation and mitochondrial DNA differentiation. All individuals with type $\mathrm{D}$ belong to one lineage of mtDNA, whereas those with type $M$ and $L$ to another lineage[23]. These data strongly imply that cryptic speciation might have occurred in local populations of $D$. lacertosa, and its Yunnan population might have reached the species level.

\section{ACKNOWLEDGEMENTS}

We are grateful to Dr. MJ Toda (Hokkaido University), Dr. QT Zeng (Hubei University), Dr. HW Chen (Tokyo Metropolitan University, TMU), Dr. JJ Gao (Kunming Institute of Zoology, KIZ), Mr. BC Wang (KIZ), Dr. JG Xiang-Yu (KIZ), Miss. C Tanaka (TMU), Mr. S Saito (TMU), Mr. A Nozawa (TMU) and Mr. H Ito (Hokkaido University of Education) for their help in field collection and stocks. We also thank Dr. XZ. Zheng (University of Pennsylvania Medical School) and Dr. XC Liang (KIZ) for invaluable discussion on the earlier version of the manuscript. The present work was supported by National Natural Science Foudation of China, (No. 39930100, 30024004), Chinese Academy of Science (No. KSCX21-05) and Japan Society for the Promotion of Science (No. 12375002) 


\section{REFERENCE}

1 White MJD. Modes of speciation. W. H. Freeman Press: San Francisco. 1978.

2 Patterson JT, Stone WS. Evolution in the genus Drosophila. New York, Macmillan Co. 1952.

3 Miller DD, Stone LE. Reinvestigation of karyotype in Drosophila affinis Sturtevant and related species. J Hered 1962; 53: 12-24.

4 Wilson FD, Wheeler MR, Harget M, Kambysellis M. Cytogenetic relations in the Drosophila nasuta subgroup of the immigrans group of species. Univ Tex Publs 1969; 6918:207-53.

5 Baimai V. Karyotype variation in Drosophila birchii Chromosoma 1969; 27:381-94.

6 Baimai V, Chumchong C. Karyotype variation and geographic distribution of the three sibling species of the Drosophila Kikkawai complex. Genetica 1980; 54:113-20.

7 Baimai V, Trapakvasin A, Kitagawa O. Additional data on metaphase karayotype variation and graphic distribution of the Drosophila kikkawai complex. Jpn J Genet 1986; 61:20716.

8 Ling FY, Wang W. A new karyotype of Drosophila albomicans. Acta Genetica Sinica 1997; 24:496-500.

9 Baimai V. Population cytogenetics of the malaria vector Anopheles leucosphyrus group. Southeast Asian J Trop Med Pub Hlth 1988; 19:668-80.

10 Baimai V. Heterochromatin accumulation and karyotypic evolution in some Dipteran insects. Zoological Studies 1998; 37:75-88.

11 Gupta JP, Sundaran AK. Some evidence of incipient speciation in Drosophila kikkawai. Genome 1994; 37:1041-4.

12 Lambert DM. Cytogenetic Evidence of a Possible Fourth Cryptic Species Within the Taxon Anopheles marshallii (Theobald) (Diptera: Culicidae) from Northern Natal. Mosquito Systematics $1981 ; 13: 168-75$.
13 Subbarao SK, Vasantha K, Adak T, Sharma VP. Anopheles culicifacies complex: evidence for a new sibling species, species C. Ann Entomol Soc Amer 1983; 76:985-8.

14 Levitan N. The robusta and melanica groups. In: Ashburner M, Carson HL, Thompson JN, Eds. The genetics and biology of Drosophila, Vol 3b. Academic Press: London 1982:141-92.

15 Narayanan Y. The phylogenetic relationships of the members of the Drosophila robusta group. Genetics 1973; 73:319-50.

16 Ling FY, Zhang WX. Studies on the karyotypes of some Chinese Drosophilid flies. Zoological Research 1987; 8:410-12.

17 Watabe H, Park J, Aotsuka T. A karyotype study of the Drosophila robusta species-group (Diptera:Drosophilidae). Zoological science 1997; 14:855-8.

18 Mayr E. Populations, Species, and Evolution. Harvard University Press: New York, 1974.

19 Powell JR. Process and prospects in evolutionary biology. The Drosophila model. Oxford university press: New York and Oxford 1997; 306.

20 Papaceit M, Juan E. Fate of dot chromosome genes in Drosophila willistoni and Scaptodrosophila lebanonensis determined by in situ hybridization. Chromosome Res 1998; 6:49-54.

21 White MJD. Animal cytology and evolution, $3^{\text {rd }}$ ed. Cambridge University Press: London 1973:334-405.

22 Watabe H, Nakata S. A comparative study of genitalia of the Drosophila roubsta and D. melanica species-group (Dipetera: Drosophilidae). J Hokkaido Univ of Education Ser. IIB. 1989; 40:1-18.

23 He LP, Watabe H, Liang XC, Zhang YP, Aotsuka T. Genetic differentiation and cryptic speciation in Drosophila lacertosa (in preparation).

24 Walker TJ. Cryptic species among sound-producing ensiferan Orthoptera (Gryllidae and Tettigoniidae). Quart Rev Biol 1964; 39:345-55. 